\title{
Multi-isotope (H, C, O, S) hydrobiogeochemistry of groundwaters impacted by pyrite oxidation and carbonate dissolution in a temperate porous aquifer
}

CHRISTOPH MALIK ${ }^{2}$, ANNA-K. JENNER ${ }^{1}$, IRIS SCHMIEDINGER $^{1}$, MICHAEL E. BÖTTCHER ${ }^{1,2,3}$,

${ }^{1}$ Geochemistry \& Isotope BioGeoChemistry, Leibniz Institute for Baltic Sea Research (IOW), Warnemünde, Germany, michael.boettcher@io-warnemuende.de ${ }^{2}$ Marine Geochemistry, University of Greifswald, Germany, christoph.malik@gmx.net

${ }^{3}$ Interdisciplinary Faculty, University of Rostock, Germany

Groundwaters from a quaternary porous aquifer system and associated surface (lake) waters were investigated for their multi-isotope $(\mathrm{H}, \mathrm{C}, \mathrm{O}, \mathrm{S})$ hydrobiogeochemical composition to identify water mixing and the sources of dissolved sulfur and carbon species. The study took place in North-Eastern Germany (Mecklenburg-Western Pomerania) close to the coastline of the Baltic Sea, an area which is under impact by agricultural activity on a regional scale. The major goal was to identify the key hydrobiogeochemical processes controlling the coupled element cycles upon groundwater evolution. Besides major and minor elements also redoxsensitive trace elements and nutrients were considered.

Water isotopes of most groundwaters are positioned on the regional meteoric water line, but surface water is affected by evaporation processes. Distinguishable signatures allow quantification of those groundwaters impacted by mixing with infiltrating lake water. Major element hydrochemical and carbon isotope composition of dissolved inorganic carbon (DIC) indicates soil $\mathrm{CO}_{2}$ controlled both by $\mathrm{C} 3$ and $\mathrm{C} 4$ vegetation as one major source and a further contribution from the subterrestrial dissolution of carbonate minerals in the aquifer matrix. Also, some indications for a contribution from oxidized dissolved organic carbon (DOC) under waterunsaturated conditions are found. The origin of dissolved sulfate is clearly dominated by the subterrestrial oxidation of pyrite found in the glacial deposits of the porous aquifer with an approx. sulfur isotope composition of about -12 per mil vs. VCDT. The coupled formation of enhanced loads in dissolved iron and manganese but low nutrient concentrations are likely associated with nitrate as a major driver for pyrite oxidation, which will be further substantiated by ongoing oxygen isotope measurements on dissolved sulfate. At some sites, the enhanced sulfate load caused in-situ microbial dissimilatory sulfate reduction and in-situ transformation of DOC to DIC. 